\title{
Bacteriological incidence in pneumonia patients with pulmonary emphysema: a bacterial floral analysis using the I6S ribosomal RNA gene in bronchoalveolar lavage fluid
}

\author{
This article was published in the following Dove Press journal: \\ International Journal of COPD \\ 20 July 2017 \\ Number of times this article has been viewed
}

\author{
Keisuke Naito' \\ Kei Yamasaki' \\ Kazuhiro Yatera' \\ Kentaro Akata' \\ Shingo Noguchi' \\ Toshinori Kawanami' \\ Kazumasa Fukuda² \\ Takashi Kido' \\ Hiroshi Ishimoto ${ }^{3}$ \\ Hiroshi Mukae \\ 'Department of Respiratory Medicine, \\ 2Department of Microbiology, \\ University of Occupational and \\ Environmental Health, Japan, \\ Kitakyushu City, Fukuoka, \\ ${ }^{3}$ Second Department of Internal \\ Medicine, Nagasaki University \\ School of Medicine, Nagasaki City, \\ Nagasaki, Japan
}

\begin{abstract}
Pulmonary emphysema is an important radiological finding in chronic obstructive pulmonary disease patients, but bacteriological differences in pneumonia patients according to the severity of emphysematous changes have not been reported. Therefore, we evaluated the bacteriological incidence in the bronchoalveolar lavage fluid (BALF) of pneumonia patients using cultivation and a culture-independent molecular method. Japanese patients with communityacquired pneumonia (83) and healthcare-associated pneumonia (94) between April 2010 and February 2014 were evaluated. The BALF obtained from pneumonia lesions was evaluated by both cultivation and a molecular method. In the molecular method, $\sim 600$ base pairs of bacterial $16 \mathrm{~S}$ ribosomal RNA genes in the BALF were amplified by polymerase chain reaction, and clone libraries were constructed. The nucleotide sequences of 96 randomly selected colonies were determined, and a homology search was performed to identify the bacterial species. A qualitative radiological evaluation of pulmonary emphysema based on chest computed tomography (CT) images was performed using the Goddard classification. The severity of pulmonary emphysema based on the Goddard classification was none in $47.4 \%(84 / 177)$, mild in $36.2 \%(64 / 177)$, moderate in $10.2 \%(18 / 177)$, and severe in $6.2 \%(11 / 177)$. Using the culture-independent molecular method, Moraxella catarrhalis was significantly more frequently detected in moderate or severe emphysema patients than in patients with no or mild emphysematous changes. The detection rates of Haemophilus influenzae and Pseudomonas aeruginosa were unrelated to the severity of pulmonary emphysematous changes, and Streptococcus species - except for the $S$. anginosus group and $S$. pneumoniae - were detected more frequently using the molecular method we used for the BALF of patients with pneumonia than using culture methods. Our findings suggest that $M$. catarrhalis is more frequently detected in pneumonia patients with moderate or severe emphysema than in those with no or mild emphysematous changes on chest CT. M. catarrhalis may play a major role in patients with pneumonia complicating severe pulmonary emphysema.
\end{abstract}

Keywords: clone library method, chronic obstructive pulmonary disease, Goddard classification, molecular method, microflora, phylotype, Moraxella catarrhalis

\section{Plain language summary}

Pneumonia can be fatal in patients with pulmonary emphysema, especially in those with severe emphysematous changes, therefore accurate understanding of causative pathogens is important, but culture-based and sputum-based bacteriological information is sometimes inaccurate and inefficient. Using bronchoalveolar lavage fluid directly obtained from pneumonia lesions, bacterial phylotypes were evaluated using culture-independent method in addition to culture 
methods, and the relationship between bacterial phylotypes and the severity of emphysematous changes according to the Goddard classification were analyzed. Moraxella catarrhalis was significantly detected in the lower respiratory tract in patients with moderate and severe pulmonary emphysema compared with no and mild emphysematous changes. Detection rates of Haemophilus influenzae and Pseudomonas aeruginosa were similar according to the severity of pulmonary emphysema. In addition, oral streptococci were predominantly detected in all severities of emphysematous changes. The results of this study suggest that oral streptococci should be considered as causative pathogens in pneumonia patients with pulmonary emphysema, and $M$. catarrhalis should be taken into consideration especially in patients with severe emphysematous changes.

\section{Introduction}

Chronic obstructive pulmonary disease (COPD) is mainly caused by cigarette smoke in industrialized countries, and the number of patients with COPD has been increasing in Japan, ${ }^{1}$ Europe, ${ }^{2}$ and the United States. ${ }^{3}$ Rapid aging of the population has also been observed in industrialized countries and has been associated with an increase in the number of COPD patients. ${ }^{1}$ In addition, an increase in the mortality rate in patients with bacterial pneumonia has also been observed in these countries. ${ }^{4}$

Pulmonary emphysema is an important radiological finding in COPD patients, and lower respiratory tract infection is a major issue in patients with COPD because it is closely related to the exacerbation of COPD and mortality. ${ }^{5}$ Application of appropriate antibiotics in these patients is important for their survival, and precise bacteriological information is necessary for the proper use of antimicrobials in patients with COPD. Regarding the causative bacterial pathogens in patients with COPD exacerbation, Sethi and Murphy reported that Haemophilus influenzae is the most frequent $(13 \%-53 \%)$, followed by Streptococcus pneumoniae (4\%-33\%), Moraxella catarrhalis (7\%-20\%), and Pseudomonas aeruginosa (1\%-20\%) using sputum samples. ${ }^{6}$ However, in some cases, it is difficult to determine the causative pathogens of COPD exacerbation by using sputum culture alone, and the causative pathogen is unknown in about half of patients with lower respiratory tract infection. ${ }^{7}$ It is also difficult to determine whether or not a sputum culture directly indicates a lower respiratory tract infection. ${ }^{8}$ In addition, whether or not culture methods can accurately determine the bacterial diversity in the lower respiratory tract is another problem hampering a precise understanding of the causative bacteria in patients with COPD exacerbation. ${ }^{9-11}$
Molecular methods using $16 \mathrm{~S}$ ribosomal RNA (rRNA) gene have been used for bacteriological identification in many types of respiratory infection, such as bacterial pleurisy, ${ }^{12}$ community-acquired pneumonia $(\mathrm{CAP})^{8}$ and healthcareassociated pneumonia (HCAP). ${ }^{13}$ In addition to accurately detecting the bacterial 16S rRNA gene, the bacterial floral analysis, we use can also estimate the bacterial diversity in each clinical sample using the $16 \mathrm{~S}$ rRNA gene. ${ }^{14-17}$ Nextgeneration sequencing (NGS) methods are modalities that identify a huge amount of sequence data in a short period of time, ${ }^{18}$ whereas the Sanger sequencing method has a higher accuracy than NGS, ${ }^{19}$ and it also estimates the bacterial species since this method consists of a longer sequence analysis. Therefore, we used the Sanger method to estimate each bacterial species and to evaluate the causative organisms in patients with pneumonia.

No study has yet been reported on the bacteriological differences in the lower respiratory tract in pneumonia patients with different severities of emphysematous changes. Therefore, we evaluated the bacteriological incidence in pneumonia patients according to the Goddard classification ${ }^{20}$ using cultivation and a culture-independent bacterial floral analysis of 16S rRNA gene sequencing in bronchoalveolar lavage fluid (BALF).

\section{Materials and methods Study population}

All 707 consecutive patients with CAP or HCAP at the University of Occupational and Environmental Health Japan and referring hospitals between April 2010 and February 2014 were enrolled in this study. Of these, 517 patients in whom bronchoscopic examinations were not performed, 7 with insufficient clinical data, and 6 with negative results of polymerase chain reaction (PCR) amplification for the 16S rRNA gene were excluded, leaving 177 patients with CAP $(n=83)$ and HCAP $(n=94)$ eventually eligible for this study (Figure 1). Among these patients, $83 \mathrm{CAP}$ and 94 HCAP patients had been included in a previous study. ${ }^{21}$

The present study was approved by the Ethics Committee of Medical Research, University of Occupational and Environmental Health, Japan (No 26-230), with the approval of each participating institution. Written informed consent was obtained from each patient before enrolling in the study. The clinical data concerning the participants, such as their age, sex, clinical manifestations, laboratory and radiological findings, and comorbid diseases, were also collected. 


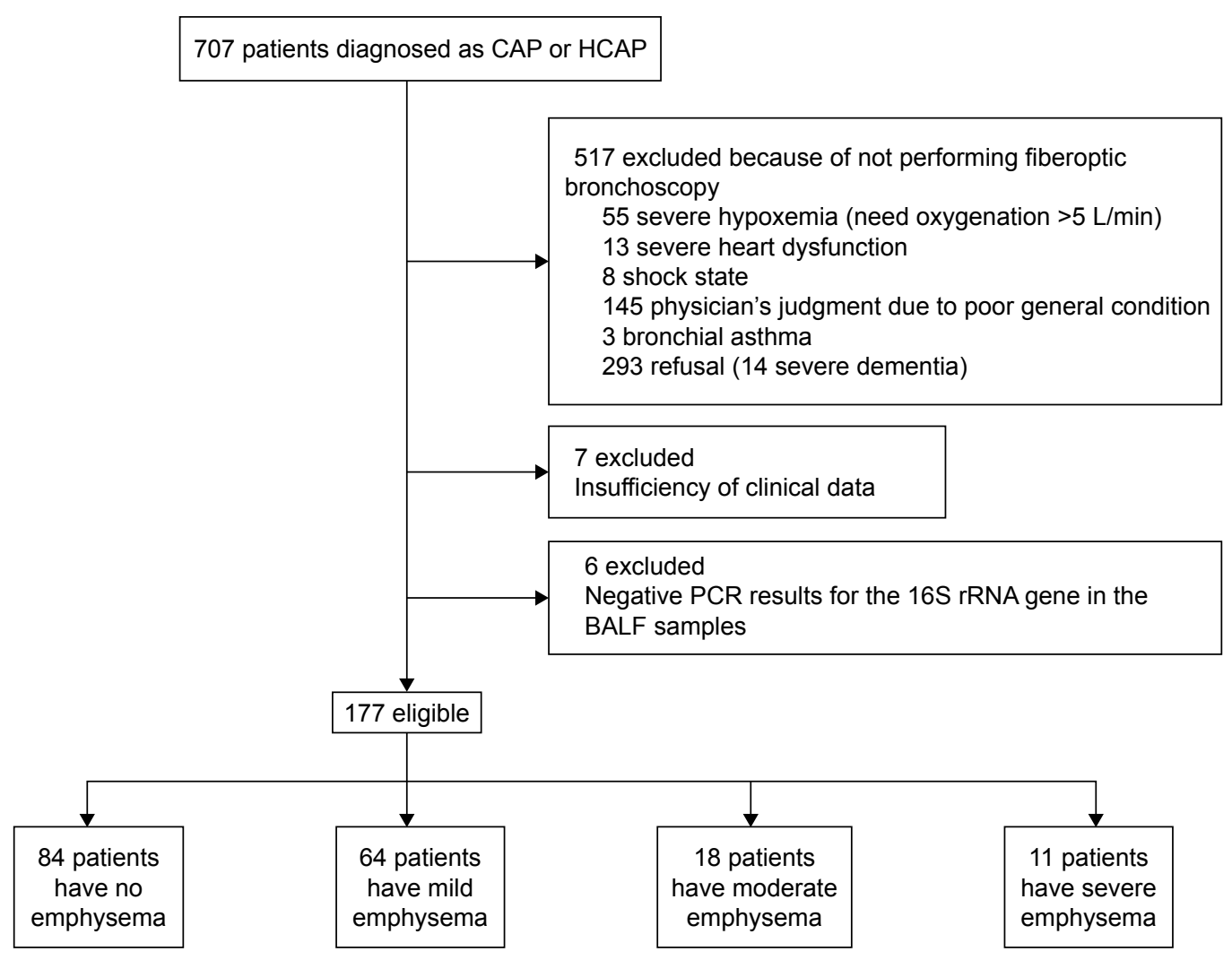

Figure I A flowchart of the exclusion and inclusion of patients and the severity of emphysema.

Abbreviations: CAP, community-acquired pneumonia; HCAP, healthcare-associated pneumonia; rRNA, ribosomal RNA; BALF, bronchoalveolar lavage fluid.

\section{Definitions}

CAP and HCAP were defined according to the guidelines of the Infectious Diseases Society of America (IDSA)/American Thoracic Society (ATS). ${ }^{22,23}$ Briefly, inpatients with new pulmonary infiltration with at least two of the following criteria were enrolled: fever $\geq 38^{\circ} \mathrm{C}$, sputum production, cough, and peripheral white blood cell count $>10,000 / \mu \mathrm{L}$. The risk factors for aspiration as defined by the criteria established by Marik were used, as previously described. ${ }^{24}$

\section{Sample collection}

Bronchofiberscopy was performed as previously described. ${ }^{8}$ Briefly, BALF specimens were obtained from the lesions of pneumonia patients using $40 \mathrm{~mL}$ of sterile saline, avoiding oral bacterial contamination during insertion of the bronchoscope.

\section{Microbiological evaluation using conventional cultivation methods}

BALF specimens were cultured under aerobic and anaerobic conditions, as previously described. ${ }^{8}$ Microbial identification was defined based on the results of positive bacterial cultures of the samples obtained from the lower respiratory tract.

\section{Total bacterial cell count and a cell lysis efficiency analysis, DNA extraction, PCR, clone library construction, determination of nucleotide sequences and homology search}

Epifluorescent microscopy was used to determine the total bacterial cell count and cell lysis efficiency for a precise evaluation of the microbiota in each sample, as previously described. ${ }^{825}$ DNA was extracted from each specimen by vigorous shaking with sodium dodecyl sulfate and glass beads, and the 16S rRNA gene sequences were amplified using a PCR thermocycler (GeneAmp PCR system 9700; Thermo Fisher Scientific, Waltham, MA, USA). The cloning of the PCR products was performed using a TOPO TA cloning kit (Thermo Fisher Scientific), and the nucleotide sequences of 96 randomly chosen colonies from each clone library were then determined using a 3130xl Genetic Analyzer (Thermo Fisher Scientific). The Phred quality values were used to select highly accurate sequences, and the sequences of the 16S rRNA gene of the type strains using the basic local alignment search tool (BLAST) algorithm were compared to estimate the bacterial phylotype, as described previously. ${ }^{8,25}$ 


\section{Definition of mono- or mixed-bacteria groups using the molecular method}

We defined the "mono-bacteria" group as patients in whom the predominant phylotype comprised $>80 \%$ of the detected bacterial phylotypes using the clone library method; the remaining patients were categorized as the "mixed-bacteria" group. ${ }^{8,13,26}$ In the mixed-bacteria group, bacterial phylotypes that occupied $>5 \%$ of the sample and the three most frequent bacterial phylotypes in each sample were evaluated.

\section{Radiological evaluation of chest high-} resolution computed tomography (HRCT): a visual evaluation of pulmonary emphysema Chest HRCT was performed just before the bronchoscopic examination. The findings of chest HRCT images were scored using the Goddard classification, ${ }^{20}$ which is a visual scale in which the areas of vascular disruption and low attenuation are scored for each lung field. Scoring was performed by two expert respirologists (KY and TK) who had been blinded to any clinical information. The definitions of the score were as follows: no abnormality, $0 ;<25 \%, 1 ;<50 \%$, $2 ;<75 \%, 3 ; 100 \%$ or almost total absence of normal lung tissue, 4. With $6 \mathrm{CT}$ slices per patient, the maximum possible score was 24 . The averages of the total points measured by the two expert respirologists were used for the classification of the severity of emphysema; 0 points was "none," 1-7 points was "mild," 8-15 points was "moderate," and $\geq 16$ points was "severe."

\section{Statistical analyses}

The baseline characteristics were summarized using descriptive statistics. Continuous variables were compared using the Mann-Whitney $U$ test and Student's $t$-tests, whereas categorical variables were compared using Fisher's exact test or the chi-squared test, as appropriate. The SPSS software package (version 19; IBM Corporation, Armonk, NY, USA)

Table I Clinical features of patients

\begin{tabular}{|c|c|c|c|c|}
\hline Variables & $\begin{array}{l}\text { No } \\
\text { emphysema }(n=84)\end{array}$ & $\begin{array}{l}\text { Mild } \\
\text { emphysema }(n=64)\end{array}$ & $\begin{array}{l}\text { Moderate } \\
\text { emphysema }(n=18)\end{array}$ & $\begin{array}{l}\text { Severe } \\
\text { emphysema }(n=I I)\end{array}$ \\
\hline Age, years, mean (SD) & $65.7(18.5)$ & $73.0(15.7)$ & $77.2(6.8)$ & $77.4(7.5)$ \\
\hline \multicolumn{5}{|l|}{ Gender } \\
\hline Male, n (\%) & $4 \mid(48.8)$ & $39(60.9)$ & $17(94.4)$ & $9(81.8)$ \\
\hline \multicolumn{5}{|l|}{ PSI score, n (\%) } \\
\hline I-III & $58(69.0)$ & $48(75.0)$ & $18(100)$ & $10(90.9)$ \\
\hline IV & $22(26.2)$ & $14(21.9)$ & $0(0)$ & $0(0)$ \\
\hline V & $4(4.8)$ & $2(3.1)$ & $0(0)$ & I (9.1) \\
\hline $\mathrm{BMI}, \mathrm{kg} / \mathrm{m}^{2}$, mean $(\mathrm{SD})^{\mathrm{a}}$ & $20.8(4.7)$ & $20.5(4.8)$ & $18.2(3.2)$ & $17.2(3.4)$ \\
\hline Risk of the aspiration, $\mathrm{n}(\%)$ & $38(45.2)$ & $31(48.4)$ & II (6I.I) & $3(27.3)$ \\
\hline \multicolumn{5}{|l|}{ ECOG PS, median (IQR) } \\
\hline 0-I; n (\%) & $56(66.7)$ & $34(53.1)$ & $5(27.8)$ & $6(54.5)$ \\
\hline $2 ; n(\%)$ & $10(11.9)$ & $17(26.6)$ & $5(27.8)$ & $2(18.2)$ \\
\hline $3-4 ;$ n (\%) & $18(21.4)$ & $13(20.3)$ & $8(44.4)$ & $3(27.3)$ \\
\hline \multicolumn{5}{|l|}{ Smoking, n (\%) } \\
\hline Smoker & $5(6.0)$ & $6(9.4)$ & $4(22.2)$ & $0(0)$ \\
\hline Ex-smoker & $24(28.5)$ & $19(29.7)$ & $8(44.4)$ & $9(81.8)$ \\
\hline Non-smoker & $45(53.5)$ & $31(48.4)$ & $2(11.1)$ & I $(9.1)$ \\
\hline $\mathrm{BI}(\mathrm{SD})^{\mathrm{c}}$ & 300.7 (528.8) & $392.8(498.3)$ & $966.8(615.1)$ & I,447 (747.7) \\
\hline \multicolumn{5}{|l|}{ Comorbidity; n (\%) } \\
\hline Bronchiectasis & $7(8.3)$ & $10(15.6)$ & $0(0)$ & I (9.I) \\
\hline Lung cancer & $5(6.0)$ & $3(4.7)$ & I (5.6) & I (9.1) \\
\hline Interstitial pneumonia & $2(2.4)$ & $9(14.1)$ & $2(I I . I)$ & $2(18.2)$ \\
\hline Cerebrovascular disease & $13(15.5)$ & $13(20.3)$ & $2(I I . I)$ & $2(18.2)$ \\
\hline Neuromuscular diseases & $12(14.3)$ & $6(9.4)$ & I (5.6) & $0(0)$ \\
\hline Dementia & $12(14.3)$ & $8(12.5)$ & $5(27.8)$ & I (9.I) \\
\hline Diabetes mellitus & $18(21.4)$ & $13(20.3)$ & I (5.6) & $2(18.2)$ \\
\hline Malignancy excluding lung cancer & $17(20.2)$ & $22(34.4)$ & $2(11.1)$ & $3(27.3)$ \\
\hline Congestive heart failure & $9(10.7)$ & $4(6.3)$ & $0(0)$ & $3(27.3)$ \\
\hline Chronic kidney disease & $8(9.5)$ & $8(12.5)$ & I (5.6) & I (9.I) \\
\hline Chronic liver disease & $3(3.6)$ & $4(6.3)$ & $0(0)$ & I (9.1) \\
\hline Respiratory failure; n (\%) & $26(31.0)$ & $26(40.6)$ & $5(27.8)$ & $4(36.4)$ \\
\hline In-hospital mortality & $3(3.6)$ & $4(6.3)$ & $3(16.7)$ & $2(I 8.2)$ \\
\hline
\end{tabular}

Note: ${ }^{\mathrm{B}} \mathrm{BMI},{ }^{\mathrm{b}}$ smoking, and ${ }^{\mathrm{C}} \mathrm{BI}$ were evaluated in 142 , I54, and 153 patients, respectively.

Abbreviations: SD, standard deviation; IQR, interquartile range; PSI, pneumonia severity index; BMI, body mass index; ECOG PS, Eastern Cooperative Oncology Group performance status; BI, Brinkman index. 
was used for the statistical analyses, and a $P<0.05$ was considered statistically significant.

\section{Results}

\section{Patient characteristics}

The characteristics of the 177 patients (CAP, 83; HCAP, 94) are shown in Table 1. The pulmonary emphysema severity based on the Goddard classification was none in $47.4 \%(84 / 177)$, mild in $36.2 \%$ (64/177), moderate in $10.2 \%$ $(18 / 177)$, and severe in $6.2 \%(11 / 177)$. The average patient age was 65.7 (range: 16-94), 73.0 (16-93), 77.2 (67-86), and 77.4 (61-87) years for none, mild, moderate, and severe emphysema, respectively. The rate of patients who have the risk of aspiration was $45.2 \%$ (38/84), 48.4\% (31/64), $61.1 \%(11 / 18)$, and $27.3 \%$ (3/11) for none, mild, moderate, and severe emphysema, respectively. The rate of CAP in patients with no or mild emphysema was $85.5 \%$ (71/83), and the rate in those with moderate or severe emphysema was $14.5 \%$ (12/83). Similarly, the rate of HCAP in patients with no or mild emphysema was $81.9 \%$ (77/94), and the rate in those with moderate or severe emphysema was $18.1 \%$ (17/94). The in-hospital mortality tended to be higher in patients with more severe emphysema under the Goddard classification, and a significantly higher in-hospital mortality was observed in patients with moderate or severe emphysema than in those with no emphysema $(P=0.032$ and 0.041 , respectively; Table 1). A higher in-hospital mortality was observed in patients with moderate or severe emphysema $(17.2 \%, 5 / 29)$ than in those with no or mild emphysema $(4.7 \%, 7 / 148)(P=0.029)$.

\section{Counting of the bacterial cells in BALF using epifluorescent microscopy}

The efficiency of cell lysis was maintained at $\geq 90 \%$ in all the samples. The epifluorescent microscopic analysis showed that the number of bacteria in the BALF samples ranged from $1.2 \times 10^{4}$ to $3.7 \times 10^{9}$ cells $/ \mathrm{mL}$ (median: $2.8 \times 10^{6}$ cells $/ \mathrm{mL}$ ) in all patients. The median bacterial counts in BALF in patients with no, mild, moderate, and severe emphysema were $3.4 \times 10^{6}$ (range: $1.2 \times 10^{4}$ to $\left.6.6 \times 10^{8}\right), 2.5 \times 10^{6}\left(1.2 \times 10^{4}\right.$ to $\left.3.7 \times 10^{9}\right), 1.2 \times 10^{6}\left(2.5 \times 10^{4}\right.$ to $\left.9.2 \times 10^{7}\right)$, and $2.4 \times 10^{6}\left(3.1 \times 10^{4}\right.$ to $2.6 \times 10^{7}$ ) cells $/ \mathrm{mL}$, respectively, and there were no significant differences between the severity groups.

\section{A comparison of the predominant bacterial isolates using conventional cultivation methods and bacterial phylotypes determined using the clone library method in relation to the severity of emphysema}

Table 2 shows the results of bacterial culture, and Table 3 shows the detected bacterial phylotypes using the bacterial floral analysis of $16 \mathrm{~S}$ rRNA gene in BALF. These sequences

Table 2 Bacteria according to the bacterial floral analysis using the conventional cultivation methods

\begin{tabular}{|c|c|c|c|c|c|c|c|}
\hline & \multicolumn{7}{|c|}{ BALF culture } \\
\hline & Total & $\begin{array}{l}\text { No } \\
\text { emphysema }\end{array}$ & $\begin{array}{l}\text { Mild } \\
\text { emphysema }\end{array}$ & $\begin{array}{l}\text { Moderate } \\
\text { emphysema }\end{array}$ & $\begin{array}{l}\text { Severe } \\
\text { emphysema }\end{array}$ & $\begin{array}{l}\text { No and mild } \\
\text { emphysema }\end{array}$ & $\begin{array}{l}\text { Moderate and } \\
\text { severe emphysema }\end{array}$ \\
\hline \multicolumn{8}{|l|}{ Important organisms } \\
\hline Streptococcus spp. (except & $8(4.4)$ & $2(2.4)$ & $4(6.7)$ & $2(8.3)$ & $0(0.0)$ & $6(4.2)$ & $2(5.6)$ \\
\hline \multicolumn{8}{|c|}{ S. pneumoniae, S. anginosus group) } \\
\hline Haemophilus influenzae & $23(12.8)$ & II (I3.I) & $8(13.3)$ & $2(8.3)$ & $2(16.7)$ & $19(13.2)$ & $4(\mathrm{II} . \mathrm{I})$ \\
\hline Streptococcus pneumoniae & $21(1 \mathrm{l} .7)$ & $13(15.5)$ & $6(10.0)$ & I (4.2) & I (8.3) & $19(13.2)$ & $2(5.6)$ \\
\hline Moraxella catarrhalis & $7(3.9)$ & $\mathrm{I}(\mathrm{I} .2)$ & $3(5.0)$ & I (4.2) & $2(16.7)$ & $4(2.8)$ & $3(8.3)$ \\
\hline Pseudomonas aeruginosa & $18(10.0)$ & $5(6.0)$ & $8(13.3)$ & $4(16.7)$ & I (8.3) & $13(9.0)$ & $5(13.9)$ \\
\hline \multicolumn{8}{|l|}{ Staphylococcus aureus } \\
\hline Methicillin-susceptible S. aureus & $7(3.9)$ & $4(4.8)$ & $3(5.0)$ & $0(0.0)$ & $0(0.0)$ & $7(4.9)$ & $0(0.0)$ \\
\hline Methicillin-resistant S. aureus & $14(7.8)$ & $5(6.0)$ & $7(11.7)$ & I (4.2) & I (8.3) & $12(8.3)$ & $2(5.6)$ \\
\hline Gram-positive organisms & $5(2.8)$ & $2(2.4)$ & $3(5.0)$ & $0(0.0)$ & $0(0.0)$ & $5(3.5)$ & $0(0.0)$ \\
\hline \multicolumn{8}{|l|}{ Gram-negative organisms } \\
\hline Klebsiella spp. & $12(6.7)$ & $2(2.4)$ & $5(8.3)$ & $5(20.8)$ & $0(0.0)$ & $7(4.9)$ & $5(13.9)$ \\
\hline Escherichia coli & $5(2.8)$ & $4(4.7)$ & I (I.7) & $0(0.0)$ & $0(0.0)$ & $5(3.5)$ & $0(0.0)$ \\
\hline Other Gram-negative organisms & $12(6.7)$ & $4(4.8)$ & $0(0.0)$ & $3(12.5)$ & $5(4 I .7)$ & $4(2.8)$ & $8(22.2)$ \\
\hline Anaerobic organisms & $8(4.4)$ & $8(9.5)$ & $0(0.0)$ & $0(0.0)$ & $0(0.0)$ & $8(5.6)$ & $0(0.0)$ \\
\hline Other organisms & $3(1.7)$ & $\mathrm{I}(\mathrm{I} .2)$ & $\mathrm{I}(\mathrm{I} .7)$ & I (4.2) & $0(0.0)$ & $2(1.4)$ & I (2.8) \\
\hline Oral bacteria & $37(20.6)$ & $22(26.2)$ & II (I8.3) & $4(16.7)$ & $0(0.0)$ & $33(23.0)$ & $4(1 \mathrm{l} .1)$ \\
\hline No growth & 32 & 16 & 10 & 3 & 3 & 26 & 6 \\
\hline Total isolates & 180 & 84 & 60 & 24 & 12 & 144 & 36 \\
\hline
\end{tabular}

Notes: Data are presented as n (\%). Percentages refer to the total number of isolates except "No growth."

Abbreviation: BALF, bronchoalveolar lavage fluid. 
Table 3 Bacteria according to the bacterial floral analysis using the I6S ribosomal RNA gene

\begin{tabular}{|c|c|c|c|c|c|c|c|}
\hline & \multicolumn{7}{|c|}{ Clone library method } \\
\hline & Total & $\begin{array}{l}\text { No } \\
\text { emphysema }\end{array}$ & $\begin{array}{l}\text { Mild } \\
\text { emphysema }\end{array}$ & $\begin{array}{l}\text { Moderate } \\
\text { emphysema }\end{array}$ & $\begin{array}{l}\text { Severe } \\
\text { emphysema }\end{array}$ & $\begin{array}{l}\text { No and mild } \\
\text { emphysema }\end{array}$ & $\begin{array}{l}\text { Moderate and } \\
\text { severe emphysema }\end{array}$ \\
\hline \multicolumn{8}{|l|}{ Important organisms } \\
\hline Streptococcus spp. (except & $68(18.8)$ & $27(15.9)$ & $27(20.8)$ & $8(21.6)$ & $6(24.0)$ & $54(18.0)$ & $14(22.6)$ \\
\hline \multicolumn{8}{|c|}{ S. pneumoniae, S. anginosus group) } \\
\hline Haemophilus influenzae & $33(9.1)$ & $16(9.4)$ & $12(9.2)$ & $3(8.1)$ & $2(8.0)$ & $28(9.3)$ & $5(8.1)$ \\
\hline Streptococcus pneumoniae & $30(8.3)$ & $17(10.0)$ & $10(7.7)$ & I (2.7) & $2(8.0)$ & $27(9.0)$ & $3(4.8)$ \\
\hline Moraxella catarrhalis & $10(2.8)$ & $2(1.2)$ & $3(2.3)$ & $2(5.4)$ & $3(12.0)$ & $5(I .7)$ & $5(8.1)$ \\
\hline Pseudomonas aeruginosa & 14 (3.9) & $5(2.9)$ & $7(5.4)$ & $0(0.0)$ & $2(8.0)$ & $12(4.0)$ & $2(3.2)$ \\
\hline Staphylococcus aureus (I6S) & $13(3.6)$ & $6(3.5)$ & $6(4.6)$ & $0(0.0)$ & $\mathrm{I}(4.0)$ & $12(4.0)$ & $\mathrm{I}(\mathrm{I} .6)$ \\
\hline \multicolumn{8}{|l|}{ Gram-positive organisms } \\
\hline Streptococcus anginosus group & $12(3.3)$ & $5(2.9)$ & $4(3.1)$ & $3(8.1)$ & $0(0.0)$ & $9(3.0)$ & $3(4.8)$ \\
\hline Corynebacterium spp. & $12(3.3)$ & $6(3.5)$ & $4(3.1)$ & $2(5.4)$ & $0(0.0)$ & $10(3.3)$ & $2(3.2)$ \\
\hline Gemella spp. & II (3.0) & $4(2.4)$ & $5(3.8)$ & $2(5.4)$ & $0(0.0)$ & $9(3.0)$ & $2(3.2)$ \\
\hline Other Gram-positive organisms & $23(6.4)$ & $9(5.3)$ & $8(6.2)$ & $4(10.8)$ & $2(8.0)$ & $17(5.7)$ & $6(9.7)$ \\
\hline \multicolumn{8}{|l|}{ Gram-negative organisms } \\
\hline Neisseria spp. & $10(2.8)$ & $4(2.4)$ & $4(3.1)$ & I (2.7) & I (4.0) & $8(2.7)$ & $2(3.2)$ \\
\hline Other Gram-negative organisms & $25(6.9)$ & $14(8.2)$ & $3(2.3)$ & $6(16.2)$ & $2(8.0)$ & $17(5.7)$ & $8(14.5)$ \\
\hline Mycoplasma pneumoniae & $15(4.1)$ & II (6.5) & $4(3.1)$ & $0(0.0)$ & $0(0.0)$ & I5 (5.0) & $0(0.0)$ \\
\hline \multicolumn{8}{|l|}{ Anaerobic organisms } \\
\hline Prevotella spp. & $33(9.1)$ & $19(11.2)$ & $12(9.2)$ & $2(5.4)$ & $0(0.0)$ & $31(10.3)$ & $2(3.2)$ \\
\hline Fusobacterium spp. & $15(4.1)$ & $8(4.7)$ & $6(4.6)$ & I (2.7) & $0(0.0)$ & $14(4.7)$ & $\mathrm{I}(\mathrm{I} .6)$ \\
\hline Veillonella spp. & $16(4.4)$ & $8(4.7)$ & $6(4.6)$ & $0(0.0)$ & $2(8.0)$ & $14(4.7)$ & $2(3.2)$ \\
\hline Other anaerobic organisms & $20(5.5)$ & $8(4.7)$ & $9(6.9)$ & I (2.7) & $2(8.0)$ & $17(5.7)$ & $3(4.8)$ \\
\hline Other organisms & $2(0.6)$ & $\mathrm{I}(0.6)$ & $0(0.0)$ & $\mathrm{I}(2.7)$ & $0(0.0)$ & I $(0.3)$ & $\mathrm{I}(1.6)$ \\
\hline Total identified phylotypes & $362^{\mathrm{a}}$ & 170 & 130 & 37 & 25 & 300 & 62 \\
\hline
\end{tabular}

Notes: Data are presented as $n$ (\%). aln the mixed-bacteria group, bacterial phylotypes that occupied $>5 \%$ of the sample and the most three frequent bacterial phylotypes in each sample were evaluated.

have been registered with DNA Data Bank of Japan (accession numbers AB787661-AB792640, LC260709LC268828). According to the bacterial floral analysis using the 16S rRNA gene in BALF, M. catarrhalis was frequently detected in patients with more severe emphysema and significantly more frequently detected in patients with moderate and severe emphysema than in those with no or mild emphysema $(P=0.016)$. In contrast, the ratios of $H$. influenzae and $P$. aeruginosa in BALF were not related to the severity of pulmonary emphysema in patients with pneumonia.

Table 4 shows the risk factors for the detection of P. aeruginosa. Similar to the findings of a previous report, ${ }^{27}$

Table 4 Fourteen patients that Pseudomonas aeruginosa was detected using the I6S ribosomal RNA gene

\begin{tabular}{|c|c|c|c|c|c|c|}
\hline \multirow[t]{2}{*}{ Case no } & \multirow[t]{2}{*}{ Age/sex } & \multicolumn{4}{|c|}{ Risk factor of Pseudomonas aeruginosa } & \multirow{2}{*}{$\begin{array}{l}\text { Severity of } \\
\text { emphysema }\end{array}$} \\
\hline & & Bronchiectasis & $\begin{array}{l}\text { Frequent exposure } \\
\text { to antibiotics }\end{array}$ & Corticosteroid use & $\begin{array}{l}\text { Old } \\
\text { tuberculosis }\end{array}$ & \\
\hline I & $70 / F$ & + & + & - & - & No \\
\hline 2 & $64 / F$ & + & + & - & - & Mild \\
\hline 3 & $80 / F$ & + & + & - & - & Mild \\
\hline 4 & $70 / F$ & + & - & + & - & Mild \\
\hline 5 & $66 / F$ & + & - & - & - & No \\
\hline 6 & $73 / F$ & + & - & - & - & Mild \\
\hline 7 & $72 / F$ & + & - & - & - & Mild \\
\hline 8 & $65 / F$ & - & + & - & - & No \\
\hline 9 & $83 / M$ & - & + & - & - & Mild \\
\hline 10 & $56 / M$ & - & - & + & - & No \\
\hline 11 & $76 / M$ & - & - & + & - & Mild \\
\hline 12 & $69 / M$ & - & - & + & - & Severe \\
\hline 13 & $64 / M$ & - & - & - & - & No \\
\hline 14 & $7 I / M$ & - & - & - & - & Severe \\
\hline
\end{tabular}

Note: Only case 13 and 14 patients had no risk factor of Pseudomonas aeruginosa.

Abbreviations: $M$, male; F, female. 
bronchiectasis, corticosteroid use, frequent exposure to antibiotics, and a history of tuberculosis were found to be risk factors for detecting $P$. aeruginosa. Most of the patients in whom $P$. aeruginosa was detected had at least one risk factor for $P$. aeruginosa (12/14), and one of the remaining two patients with no risk factors had no emphysematous changes.

\section{Discussion}

No data have yet been provided to support any relationship between the causative pathogens of pneumonia using BALF samples and the severity of pulmonary emphysema. The present study using a bacterial floral analysis with the 16S rRNA gene in addition to culture methods in BALF in CAP and HCAP patients revealed for the first time that Streptococcus spp. were most frequently primarily detected in patients with moderate to severe pulmonary emphysema using the Goddard classification, in addition to well-known pathogens, such as H. influenzae, S. pneumoniae, and M. catarrhalis. In addition, $M$. catarrhalis was more frequently detected in patients with moderate and severe emphysema than in those with no or mild emphysema $(P=0.016$; Table 3$)$.

Previous studies in COPD patients with pulmonary emphysematous changes reported an increased exacerbation frequency in patients with increased severity of emphysema in addition to a high GOLD staging. ${ }^{28}$ The causative bacterial pathogens for an exacerbation of COPD have been reported to be $H$. influenzae, $S$. pneumoniae, $M$. catarrhalis, and $P$. aeruginosa using sputum samples. ${ }^{6}$ However, there have been no reports evaluating the causative pathogens using BALF samples directly obtained from pneumonia lesions, and no studies have investigated the relationship between the bacterial flora in the lung (as evaluated by both bacterial culture and a molecular method) and the severity of pulmonary emphysema in patients with pneumonia. To our knowledge, this study is the first to compare the results of culture and a molecular method in BALF samples obtained from patients with different severities of pulmonary emphysema.

Regarding $H$. influenzae being the most frequently detected bacteria in sputum samples in patients with COPD exacerbation, the ratios of $H$. influenzae in BALF were similar in all groups of pulmonary emphysema severity $(8 \%-14 \%)$ in both culture and in the bacterial floral analysis of $16 \mathrm{~S}$ rRNA gene. In addition, the detection rate of $H$. influenzae was lower in this study than in a previous report. ${ }^{6}$

Of note, in the present study, not only the ratio of $H$. influenzae but also the ratio of each detected bacterial species was lower than that in a previous report. ${ }^{6}$ Previous results have described the ratio of detected bacterial species only in patients in whom the causative bacteria was known; however, the causative bacteria is unknown in about half of patients. ${ }^{6}$ Furthermore, some bacteria were detected at a higher rate in the BALF $(96.7 \%, 177 / 183)$ in patients in the present study than in previous studies. The molecular method we used detected anaerobes, such as Prevotella spp. and Fusobacterium spp., Mycoplasma pneumoniae and Streptococcus spp., at a higher rate than culture; as such, the detection rates of common bacteria such as $H$. influenzae, $S$. pneumoniae, $M$. catarrhalis, and $P$. aeruginosa might be lower than in previous studies.

The detection rates of Streptococcus spp. differed between culture and the molecular method using the $16 \mathrm{~S}$ rRNA gene. Table 3 shows that the most frequently detected bacterial phylotype was Streptococcus spp. aside from the S. anginosus group (22.6\%, 14/42 bacterial phylotypes) in patients with moderate or severe emphysematous changes. In a review of 14 studies evaluating the causative pathogens of COPD exacerbation, ${ }^{6}$ none found Streptococcus spp. to be frequent causative bacteria, and this bacterial group had not been considered a causative pathogen of COPD exacerbation. In addition, Streptococcus spp. were detected in 5 of 26 bacterial phylotypes among 12 fatal patients of a total of 177 patients in the present study. These results suggest that Streptococcus spp. tend to be underestimated when culture methods are applied, and they might be the causative pathogens for severe pneumonia as well as mild pneumonia.

In contrast, culture was able to identify Streptococcus spp. in BALF in only 5.6\% (2/36 bacterial phylotypes) of patients, a detection rate about one-quarter of that of the molecular method, and there were many cases in which the causative pathogens were undetectable, detecting only oral bacteria or "no growth" using culture methods of BALF. Similar phenomena may be seen in real-world clinical settings, and Streptococcus spp. other than $S$. anginosus group may be underestimated and underdiagnosed as causative pathogens of pneumonia. Therefore, similar to $S$. anginosus group physicians should consider Streptococcus spp. other than $S$. anginosus group as potential causative pathogens of pneumonia with emphysematous changes.

M. catarrhalis is a major bacterial pathogen in patients with COPD exacerbation. Our results showed that $M$. catarrhalis in BALF was detected at a higher rate in patients with moderate to severe emphysematous changes $(8.1 \%, 5 / 62$ bacterial phylotypes) than in those with no or mild emphysematous changes $(1.7 \%, 5 / 300$ bacterial phylotypes) $(P=0.016)$. In addition, the ratio of $M$. catarrhalis was the same as that of $H$. influenzae, a well-known pathogen, in 
patients with moderate or severe emphysematous changes. Given our results, $M$. catarrhalis should be considered as a potential causative pathogen in pneumonia patients with emphysematous changes.

$H$. influenzae was the second most frequently detected bacterial phylotype following Streptococcus spp. in our study. $H$. influenzae is a well-known bacterial pathogen associated with COPD exacerbation, but the detection rate of $H$. influenzae was not related to the severity of pulmonary emphysema in this study, being observed at a rate of $9.3 \%$ (28/300) in patients with no or mild emphysematous changes and at $8.1 \%$ (5/62 bacterial phylotypes) in those with moderate or severe emphysematous changes. A previous study reported that $H$. influenzae was associated with a low frequency of COPD exacerbation. ${ }^{29}$ The results concerning $H$. influenzae and the progression of pulmonary emphysema in animal models of COPD have been controversial. Moghaddam et al reported that chronic exposure to lysates of non-typeable $H$. influenzae induced airway inflammation but not emphysema or airway remodeling in mice, ${ }^{30}$ and others suggested that $H$. influenzae may contribute to the development of COPD. ${ }^{31}$ Wang et al reported that the persistent infection or colonization of H. influenzae in the lower respiratory tract in emphysematous hamsters lasted significantly longer than in normal hamsters after acute infection with H. influenzae. ${ }^{32}$ These results suggest that the pathogenic potential of $H$. influenzae may not be closely related to the severity of COPD, at least in relation to emphysematous changes, in patients with COPD exacerbation. Further investigations are necessary to elucidate the role of $H$. influenzae in the pathogenesis and exacerbation of COPD.

As a pathogen of COPD exacerbation, $P$. aeruginosa has been reported to be the second most common bacterial species following $H$. influenzae, S. pneumoniae, and M. catarrhalis. ${ }^{6,33}$ Similar to $H$. influenzae, the detection rate of $P$. aeruginosa was relatively low and was not related to the severity of emphysematous changes in our study, with detection rates of $4.0 \%$ (12/300 bacterial phylotypes) in patients with no or mild emphysematous changes and $3.2 \%$ (2/62 bacterial species) in patients with moderate or severe emphysematous changes. In addition, a higher detection rate of $P$. aeruginosa in BALF was observed for culture compared with the molecular method in this study (Table 2): 9.0\% versus $4.0 \%$ in patients with no or mild emphysematous changes and $13.2 \%$ versus $3.2 \%$ in patients with moderate or severe emphysematous changes, respectively. These differences in the detection rate of $P$. aeruginosa may be due to differences in the detection threshold between the culture method and the molecular method we used. Previous results from our institute have shown that the clone library method detected phylotypes of $P$. aeruginosa at rates less than half of those obtained using cultivation methods in patients with HCAP. ${ }^{13}$

Our results suggest that emphysematous changes might not be related to the detection of $P$. aeruginosa, although $P$. aeruginosa is commonly detected in patients with risk factors such as bronchiectasis, immunosuppressants, recent antibiotic use, and a history of tuberculosis. While the colonization of $P$. aeruginosa may be more frequently observed in patients with pulmonary emphysema than in those without emphysema, ${ }^{34}$ this pathogen might not be a very common cause of pneumonia patients with emphysematous changes. The excessive use of broad-spectrum antimicrobials may lead to an increase in antibiotic-resistant pathogens, ${ }^{27}$ and our results may facilitate more appropriate use of antibiotics in relation to covering $P$. aeruginosa, especially in mild pneumonia cases or in patients without risk factors for $P$. aeruginosa.

The bacterial floral analysis with the $16 \mathrm{~S}$ rRNA gene using BALF used in the present study generally detects a wider range of bacterial phylotypes in a given sample than culture methods. ${ }^{8,12,13}$ Indeed, the bacterial floral analysis was able to detect presumptive causative pathogenic bacterial phylotypes even in BALF samples for which the culture method could not detect any bacteria in this study. However, thanks to recent advances in molecular methods, such as the development of next-generation sequencers, microbiota, and their roles in the lower respiratory tract of patients with COPD have been evaluated; ${ }^{35}$ this increased detection rate may increase the risk of false-positive results. Given this concern, we evaluated the lung microbiota of the BALF in 30 patients with interstitial pneumonia as representative of noninfectious causes of pneumonia using this same molecular method in our previous report; ${ }^{8}$ all of the BALF specimens showed negative PCR results. The PCR results for the 16S rRNA gene were negative when the total bacterial cell counts were $<10^{4} / \mathrm{mL}$ in the BALF, so the cutoff value for "infectious" versus "non-infectious" was estimated at $\sim 10^{4}$ bacterial cells $/ \mathrm{mL}$ in the BALF sample. Given these results, we believe that the risk of false-positive results was relatively low in our method.

Previous retrospective studies have shown a higher mortality rate in CAP patients with COPD than in those without COPD ${ }^{36,37}$ However, others have reported similar mortalities in patients with and without COPD. ${ }^{38}$ Concerning the severity of pulmonary emphysematous changes and in-hospital 
mortality, the mortality of patients with moderate or severe emphysematous changes $(17.2 \%, 5 / 29)$ was significantly higher than in those with no or mild changes $(4.7 \%, 7 / 148)$ ( $P=0.029)$. Our results suggest that the grading of pulmonary emphysematous changes may be helpful for predicting the mortality risk in pneumonia patients.

\section{Study limitations}

Several limitations associated with the present study warrant mention. First, the universal primers we used for the molecular method in this study were unable to amplify all of the bacterial $16 \mathrm{~S}$ rRNA genes. Approximately $92 \%$ of the species that had been registered in the Ribosomal Database Project II database were detectable using the universal primers we used. However, none of the phylotypes undetectable with these primers $(\sim 8 \%)$ have been reported as causative pathogens in humans. Second, the number of clones analyzed using the molecular method we used in this study was $\sim 100$ per clone library. The method using bacterial 16S rRNA gene sequences that we used in this study may not be able to detect bacterial phylotypes that present with $<1 \%$ of the bacteria in each sample. Third, phagocytosis of each bacteria by leukocytes in each sample and quantitative culture was not performed.

\section{Conclusion}

We conducted a bacterial floral analysis in BALF using the 16S rRNA gene in CAP and HCAP patients with different degrees of pulmonary emphysema, and the most frequently detected bacterial phylotype was Streptococcus spp. aside from S. anginosus group. M. catarrhalis was more frequently detected in patients with moderate and severe emphysema than in those with no or mild emphysema, but the detection rates of $H$. influenzae and $P$. aeruginosa were unrelated to the severity of emphysematous changes. These results from our 16S rRNA gene analysis of BALF in pneumonia patients may improve our understanding of bacterial pathogens in pneumonia patients with emphysematous changes.

\section{Acknowledgments}

We thank Drs Chiharu Yoshii, Hideto Obata, Yukiko Kawanami, Yugo Yoshida, Takeshi Orihashi, Chinatsu Nishida, Takaaki Ogoshi, Keishi Oda, Naoyuki Inoue, Shuya Nagata, Minako Hanaka, Susumu Tokuyama, Yasuo Chojin, Yu Suzuki, Ikuko Shimabukuro, Tomoko Shiraishi, Kanako Hara, Chiyo Ito, Masanori Isa, Kaori Kato, Takashi

Tachiwada, Tetsuya Hanaka, Tsutomu Takaki, Keigo Uchimura, Yousuke Sasahara, Takanobu Johtatsu, Ryosuke
Hata, Chisato Miyoshi, Yasuhiro Kimura, Ryo Torii, Masahiro Tahara, Kazuki Sakagami, Hiroaki Ikegami, Yoko Fukuda, and Kazuhiro Uyama for collecting the samples and Ms Yoshiko Yamazaki, and Kumiko Matsuyama for their technical assistance.

This study was partially supported by the High Altitude Research Grant from the University of Occupational and Environmental Health, Japan, a Ministry of Education, Science, Sports and Culture Grant-in-Aid for Scientific Research (C), 23591173, 2011, and a Ministry of Education, Science, Sports and Culture Grant-in-Aid for Young Scientists (B), 24790828, 2012.

\section{Author contributions}

All authors contributed toward data analysis, drafting and revising the paper and agree to be accountable for all aspects of the work.

\section{Disclosure}

The authors report no conflicts of interest in this work.

\section{References}

1. Fukuchi $Y$, Nishimura M, Ichinose M, et al. COPD in Japan: the Nippon COPD Epidemiology study. Respirology. 2004;9(4):458-465.

2. Buist AS, McBurnie MA, Vollmer WM, et al. International variation in the prevalence of COPD (the BOLD Study): a population-based prevalence study. Lancet. 2007;370(9589):741-750.

3. Menezes AM, Perez-Padilla R, Jardim JR, et al. Chronic obstructive pulmonary disease in five Latin American cities (the PLATINO study) a prevalence study. Lancet. 2005;366(9500):1875-1881.

4. GBD 2013 Mortality and Causes of Death Collaborators. Global, regional, and national age-sex specific all-cause and cause-specific mortality for 240 causes of death, 1990-2013: a systematic analysis for the Global Burden of Disease Study 2013. Lancet. 2015;385(9963):117-171.

5. Soler-Cataluna JJ, Martinez-Garcia MA, Roman Sanchez P, Salcedo E, Navarro M, Ochando R. Severe acute exacerbations and mortality in patients with chronic obstructive pulmonary disease. Thorax. 2005;60(11): 925-931.

6. Sethi S, Murphy TF. Bacterial infection in chronic obstructive pulmonary disease in 2000: a state-of-the-art review. Clin Microbiol Rev 2001;14(2):336-363.

7. Sethi S, Anzueto A, Miravitlles M, et al. Determinants of bacteriological outcomes in exacerbations of chronic obstructive pulmonary disease. Infection. 2016;44(1):65-76.

8. Yamasaki K, Kawanami T, Yatera K, et al. Significance of anaerobes and oral bacteria in community-acquired pneumonia. PLoS One. 2013; 8(5):e63103.

9. Sapey E, Stockley RA. COPD exacerbations. 2: aetiology. Thorax. 2006; 61(3):250-258.

10. Bandi V, Apicella MA, Mason E, et al. Nontypeable Haemophilus influenzae in the lower respiratory tract of patients with chronic bronchitis. Am J Respir Crit Care Med. 2001;164(11):2114-2119.

11. Murphy TF, Brauer AL, Schiffmacher AT, Sethi S. Persistent colonization by Haemophilus influenzae in chronic obstructive pulmonary disease. Am J Respir Crit Care Med. 2004;170(3):266-272.

12. Kawanami T, Fukuda K, Yatera K, Kido M, Mukae H, Taniguchi H. A higher significance of anaerobes: the clone library analysis of bacterial pleurisy. Chest. 2011;139(3):600-608. 
13. Noguchi S, Mukae H, Kawanami T, et al. Bacteriological assessment of healthcare-associated pneumonia using a clone library analysis. PLoS One. 2015;10(4):e0124697.

14. Acinas SG, Anton J, Rodriguez-Valera F. Diversity of free-living and attached bacteria in offshore Western Mediterranean waters as depicted by analysis of genes encoding 16S rRNA. Appl Environ Microbiol. 1999;65(2):514-522.

15. Akiyama T, Miyamoto H, Fukuda K, et al. Development of a novel PCR method to comprehensively analyze salivary bacterial flora and its application to patients with odontogenic infections. Oral Surg Oral Med Oral Pathol Oral Radiol Endod. 2010;109(5):669-676.

16. Fredricks DN, Fiedler TL, Marrazzo JM. Molecular identification of bacteria associated with bacterial vaginosis. $N$ Engl J Med. 2005; 353(18):1899-1911.

17. Harris JK, De Groote MA, Sagel SD, et al. Molecular identification of bacteria in bronchoalveolar lavage fluid from children with cystic fibrosis. Proc Natl Acad Sci U S A. 2007;104(51):20529-20533.

18. Bertelli C, Greub G. Rapid bacterial genome sequencing: methods and applications in clinical microbiology. Clin Microbiol Infect. 2013; 19(9):803-813.

19. Shendure J, Ji H. Next-generation DNA sequencing. Nat Biotechnol. 2008;26(10):1135-1145.

20. Goddard PR, Nicholson EM, Laszlo G, Watt I. Computed tomography in pulmonary emphysema. Clin Radiol. 1982;33(4):379-387.

21. Akata K, Yatera K, Yamasaki K, et al. The significance of oral streptococci in patients with pneumonia with risk factors for aspiration: the bacterial floral analysis of $16 \mathrm{~S}$ ribosomal RNA gene using bronchoalveolar lavage fluid. BMC Pulm Med. 2016;16(1):79.

22. Mandell LA, Wunderink RG, Anzueto A, et al. Infectious Diseases Society of America/American Thoracic Society consensus guidelines on the management of community-acquired pneumonia in adults. Clin Infect Dis. 2007;44(Suppl 2):S27-S72.

23. American Thoracic Society, Infectious Diseases Society of America. Guidelines for the management of adults with hospital-acquired, ventilator-associated, and healthcare-associated pneumonia. Am J Respir Crit Care Med. 2005;171(4):388-416.

24. Marik PE. Aspiration pneumonitis and aspiration pneumonia. N Engl J Med. 2001;344(9):665-671.

25. Kawanami T, Yatera K, Fukuda K, et al. Diagnosis of fulminant pneumonia caused by Legionella pneumophila serogroup 8 with the sequence analysis of the 16S rRNA gene. Tohoku J Exp Med. 2011;225(1):65-69.
26. Mukae H, Noguchi S, Naito K, et al. The importance of obligate anaerobes and the Streptococcus anginosus group in pulmonary abscess: a clone library analysis using bronchoalveolar lavage fluid. Respiration. 2016;92(2):80-89.

27. Falguera M, Carratala J, Ruiz-Gonzalez A, et al. Risk factors and outcome of community-acquired pneumonia due to Gram-negative bacilli. Respirology. 2009;14(1):105-111.

28. Oh YM, Sheen SS, Park JH, et al. Emphysematous phenotype is an independent predictor for frequent exacerbation of COPD. Int J Tuberc Lung Dis. 2014;18(12):1407-1414.

29. Domenech A, Puig C, Marti S, et al. Infectious etiology of acute exacerbations in severe COPD patients. J Infect. 2013;67(6):516-523.

30. Moghaddam SJ, Clement CG, De la Garza MM, et al. Haemophilus influenzae lysate induces aspects of the chronic obstructive pulmonary disease phenotype. Am J Respir Cell Mol Biol. 2008;38(6): 629-638.

31. Ganesan S, Comstock AT, Kinker B, Mancuso P, Beck JM, Sajjan US. Combined exposure to cigarette smoke and nontypeable Haemophilus influenzae drives development of a COPD phenotype in mice. Respir Res. 2014;15:11.

32. Wang D, Wang Y, Liu YN. Experimental pulmonary infection and colonization of Haemophilus influenzae in emphysematous hamsters. Pulm Pharmacol Ther. 2010;23(4):292-299.

33. Sethi S. Infection as a comorbidity of COPD. Eur Respir J. 2010;35(6): 1209-1215.

34. Desai H, Eschberger K, Wrona C, et al. Bacterial colonization increases daily symptoms in patients with chronic obstructive pulmonary disease. Ann Am Thorac Soc. 2014;11(3):303-309.

35. Mammen MJ, Sethi S. COPD and the microbiome. Respirology. 2016;21(4):590-599.

36. Ruiz De Ona JM, Gomez Fernandez M, Celdran J, Puente-Maestu L. Pneumonia in the patient with chronic obstructive pulmonary disease. Levels of severity and risk classification. Arch Bronconeumol. 2003; 39(3):101-105.

37. Garcia-Vidal C, Calbo E, Pascual V, Ferrer C, Quintana S, Garau J. Effects of systemic steroids in patients with severe community-acquired pneumonia. Eur Respir J. 2007;30(5):951-956.

38. Torner N, Izquierdo C, Soldevila N, et al. Factors associated with 30-day mortality in elderly inpatients with community acquired pneumonia during 2 influenza seasons. Hum Vaccin Immunother. 2017;13(2): $450-455$.
International Journal of COPD

\section{Publish your work in this journal}

The International Journal of COPD is an international, peer-reviewed journal of therapeutics and pharmacology focusing on concise rapid reporting of clinical studies and reviews in COPD. Special focus is given to the pathophysiological processes underlying the disease, intervention programs, patient focused education, and self management protocols.

\section{Dovepress}

This journal is indexed on PubMed Central, MedLine and CAS. The manuscript management system is completely online and includes a very quick and fair peer-review system, which is all easy to use. Visit http://www.dovepress.com/testimonials.php to read real quotes from published authors. 